a whole is given to everybody, which means that every man aims at, regulated, stimulated and restricted by a certain force, exercising the verbal activity in accordance with his external or internal needs, and in such a way that could be understood by others [1, c. 35].

In modern linguistics, there exist some well-known antinomies such as «synchronic - diachronic», «statics - dynamics», «pragmatics syntagmatics», «inner and outer relations of the language», «language speech» and others. All these antinomies deal with the language from different points of view: from the historical development to the present days status, due to one of its main factors - the change of the language, due to associative and linear character of the language and of course the difference between the language as the system, which is developing constantly and the speech as its practical realization, its usage in the process of communication.

So, antinomies play the very important role in the developing of language. Due to its existence, the language can change. The exact quantity of antimonies in language is impossible to find, but all of them make the language flexible and live, the help the language to move.

\title{
References:
}

1. Гумбольдт В. фон Язык и философия культуры. М.: Прогресс, 1985. $452 \mathrm{c}$.

2. Yeremeyev Y. Language. Antinomy. Dialogue http://cogprints.soton.ac.uk/language / philosophy of language, Southampton, $2001 / /$ antinomy.narod.ru, 2001.

DOI https://doi.org/10.30525/978-9934-26-073-5-1-69

\section{INNER ASSOCIATION POWER BETWEEN ELEMENTS OF A BINOMIAL SEQUENCE}

\author{
Rizhok I. I. \\ Student \\ Ivan Franko National University of Lviv \\ Lviv, Ukraine
}

Binomials, generally defined as coordinated pairs of linguistic units that share partial semantic relations between their constituent components, are one of the most heterogeneous, and therefore, convoluted phenomena existing in the English language. In spite of the fact that they are extremely frequently 
used in daily communication, binomials remain, in the majority of cases, easily overlooked by most language users. For this particular reason the concept of binomial expressions is still full of 'grey areas' that puzzles the minds of linguists nowadays, even though it has been targeted in an extensive amount of research before.

The object of this study is the phenomenon of binomials in general, whereas the subject is the connection existing between constituent components of a binomial expression. The aim is to analyse this connection and establish if internal association strength is the unique feature that makes binomials different and is necessitated by an obligatory presence of a coordination conjunction. The tasks are as follows: to establish the role a coordinating conjunction plays in the functioning of a binomial sequence, compare the efficiency of various statistical methods to accurately measure the degree of association within a binomial, design the most adequate statistical means specifically for binomial expressions, and to test its effectiveness in comparison to other statistical types of measurement.

The novelty of this work consists in the need to study this connection which is predetermined by the lack of a clear distinction made between binomials and other types of formulaic language, collocations in particular. Owing to the lack of a rigid division between binomials and collocations, previous pieces of research had a tendency to narrow the former down to the class of bi-grams, neglecting the essential to the whole phrase conjunction and, subsequently, having the final results biased.

Previously used statistical means such as Mutual Information and loglikelihood score have appeared to be ineffective in regards to binomial sequences. MI tended to accord the highest value to the least ubiquitous constructions whereas log-likelihood value could not exclude grammatical collocations or false positives from the study.

This study, therefore, addresses the issue of finding the most adequate statistical measure that would enable obtaining the values which reflect their natural language use.

Methodologies. The study consisted of several stages: a corpus search for repetitive patterns and reoccurring regularities that featured in contemporary English particularly among the groups of binomials and collocations; the analysis of previously used statistic means in relation to binomials; the implementation of a specifically designed formula to account for an internal association connection between members of a binomial sequence, a repeated use of corpus with the aim of confirming the accuracy of achieved results.

The search was conducted on the basis of IWEB corpus. The target constructions also included multinomials. The exploration took into 
consideration both reversible, non-fixed and 'frozen', irreversible binomial expressions, with the emphasis on the former.

Findings. The study has demonstrated that a) a coordinating conjunction is the core of a binomial which functions as a mediator between elements and prevailingly takes the central position within the entire expression; b) a new modified log-r formula has successfully compensated for the incapacities of other types of measurement by including the coordination conjunction in the study; c) the results yielded on the basis of the IWEB corpus have proven to accurately reflect the bond existing between elements of a binomial taking into consideration both the frequency of separate words and the one of the whole expression and their tendency to co-occur in the same context.

\section{References:}

1. Carrol, Gareth\& Conklin, Kathy.Is all formulaic language created equal?//Unpacking the Processing Advantage for Different Types of Formulaic Sequences. Language and Speech, 2019. Accessed on 30 Sep 2020 at https://doi.org/10.1177/0023830918823230

2. Fujimura I. \& Aoki S. A New Score to Characterise Collocations // Log-r in Comparison to Mutual Information. Conference paper, July 2015. URL: https://www.researchgate.net/publivations/315653005

3. Lohnmann, Arne. English Coordinate Constructions // A Processing Perspective on Constituent Order. Cambridge University Press, 2014.

4. Malkiel Y. Studies in Irreversible Binomials // Lingua 8, 1959. P. 113-160.

5. Mollin, Sandra. The Ir(reversibility) of English Binomials // Corpus, Constraints, Development. John Benjamins Publishing Company, 2014.

6. Sauer, Hans \& Kopaczyk Joanna. Binomials in the History of English // Fixed and Flexible. Cambridge University Press, 2017. - P. 1-24. 